\title{
Human Factors Approach to Railway Safety
}

\author{
Hiroshi UGAJIN \\ Senior Researcher \\ Fundamental Research Dept., RTRI
}

\begin{abstract}
In order to prevent railway accidents and accidents at crossings from occurring due to human error, and to strive for even greater improvement in safety in railway operation, RTRI psychology and ergonomics staff are engaged in research and development in their respective fields of responsibility. The review summarizes what the staff studied from actual accidents, what methods they used to achieve the results of their research, or used to try to achieve those results. In the references, only literature published in English is given.
\end{abstract}

Keywords : railway accident, human error, labor science, safety psychology, ergonomics

\section{Roots of labor scientific accident prevention research}

The Railway Technical Research Institute is the corporation which inherited the testing and research work of the Japanese National Railways in 1987. Prior to that, one of its identities was the Railway Labor Science Research Institute (1963-1987). It is heir to accident research conducted there, but at the present, there are also the Safety Psychology Laboratory and the Ergonomics Laboratory, employing approximately 20 staff.

For Japanese railways, there are records on the surveys conducted 1923, regarding harmful substances inside tunnels. In 1926-1927, a labor physiological survey was conducted for car coupling workers and locomotive drivers. We can consider this to be the point at which ergonomics was introduced for the first time in Japanese railways. Immediately after the end of World War II , aptitude psychology was introduced, preparing the foundation for the modern aptitude test system. Physiological surveys and research had been conducted over the entire range of safety issues. A full-scale focus on human factors was taken up in the process of Shinkansen development (starting of service in 1964) 1).

Through the above processes, in 1962 a double collision accident of trains occurred at Mikawashima, resulting in 456 people killed or injured, which was caused by locomotive driver's error in failing to check a signal. This provided the impetus for the founding in the following year of the Railway Labor Science Research Institute. Here with researchers in the various fields of physiology, psychology, and engineering, we conducted testing and research ranging over a wide scope of disciplines including labor safety, work environment, workload, work aptitude, man-machine systems, as well as organizational psychology and customer psychology.

\section{Railway accidents and the human factor}

The total length of railways in operation in Japan totals approximately $27,000 \mathrm{~km}$ for all train lines. The annual total transported is approximately 400 billion passenger-kilometers. Under these circumstances, the various systematic strategies that have been previously implemented
Table 1 Classification by cause for the railway operating accidents

\begin{tabular}{clcc}
\hline Category & Cause & Number of accidents & Percentage \\
\hline Internal & Railway personnel & 24 & 2.5 \\
causes & Train car, railway equipment & 3 & 0.3 \\
\hline External & Crossing & 499 & 51.8 \\
causes & Trespassing onto train tracks & 247 & 25.6 \\
& Obstacle on the train tracks & 72 & 4.5 \\
& Other & 119 & 12.3 \\
\hline Total & & 964 & 100.0 \\
\hline
\end{tabular}

to prevent accidents have played their part. Accidents in the operation of railways are showing a downward trend. There were 964 accidents that occurred in the operation of railways in Japan in 1997. Twenty years ago approximately three times as many, and about 1.5 times as many 10 years ago were reported.

A chart showing classification by cause for the operating accidents that occurred in 1997 is given in Table 1. Among these, only $3 \%$ or less is attributable to the responsibility of railway operators and the majority of these were accidents at crossings, due to human error of persons passing through the crossing, viz., to human error of people not relating to the railway operations. These kinds of trends have not shown any significant variation over the last several years. At present the number of these crossings, large and small, is approximately 38,000.

Furthermore, if we take a look at train accidents that can easily lead to serious accidents (generally, consisting of train collisions, train derailments, general train fires), of the 32 accidents that occurred in 1997, 14 accidents were the result of handling by the person in charge, and 4 were caused at crossings. Although the number of accidents is not numerous, about $40 \%$ of these train accidents were due to human error on the part of employees. Here too there has been no change in the trends over the last several years.

It is our crucial on-going mission to keep accidents like these caused by human error from occurring again, and to contribute to establishing steps for preventing them. 


\section{Prevention of human error accident by railway employees}

\section{1 Analyzing and administering accident information}

Materials usable for considering accident prevention can be found from among detailed information about the accidents. Therefore, understanding them as accurately as possible is most crucial. This means that an accident information system comparable to that on airplanes is desirable but at present this is not feasible. Furthermore, since our institute is now a research organization independent of railway operators, obtaining accident information becomes difficult.

Under these circumstances, a special attention should be paid to a series of noteworthy researches intended to obtain concrete hints for accident prevention by clarifying the mechanism of occurrence, by focusing on the accidents for special patterns of human error. We can give examples of experimental works ${ }^{2,3}$ ) about when a mistake causes an accident (accident caused when an engineer relies on a fellow employee's signal and starts the train against the signal light) and investigative researches attempting to inquire, within the theoretical framework of "risk taking", into the action of passengers of rushing onto a train at the last minute (dangerous action by a passenger trying to jump onto a train as it starts up).

When viewing our activities from the objectives of promoting research for analyzing the elements of human error type accidents, development and proposition of a new accident survey format is noteworthy, which is composed of: (1) general accident conditions; (2) causes inducing the error; (3) specific states of the work and persons involved; (4) type of error; (5) effective steps to prevent re-occurrence.

Moreover, accidents due to engineer error largely arose from individual characteristics of the station or railway division. In many cases, analysis of accident elements, including multivariate analysis, and prediction of the degree of danger of an accident, have been frequently implemented, based upon the research how equipment characteristic of each station and each railway division is related to the evaluation by supervisor about history of an accident and the degree of danger in that area. These methods can be effectively used in driver training and in assessing effect of equipment investment.

In the next stage, we extended these procedures further, leading to development of a safety database able to handle consistently accident information input, searches, statistical processing, producing reports, etc. Then a typical accident analysis program was added to this system, and a framework for analyzing accidents for field use was set up. This is now employed by JR Companies as the "Safety Management Support System."

The probability of accidents caused by human error in normal train operation mode, through expansion of a suitable predictive mechanism, can be gradually reduced. In contrast, the importance of the impact when railway operation encounters unexpected circumstances as well as the importance of errors occurring in maintenance of cars or equipment is increasing. Research of measures for these has been intermittently conducted, but needs to be given even greater priority.
Amidst this situation, it is essential that we pay careful attention to the social and cultural circumstances the employees are placed in. In that sense, research and investigation related to social factors such as work motivation, work satisfaction, group dynamics, work place safetyrelated climate has been continuing, but at present we are aiming to systemize these efforts under the theme of "Research of a Cognitive and Social Psychology Model of Human Error" 4).

\section{2 Selection and training of personnel}

It is essential that personnel concerned with train operation have passed aptitude screening for operating a train. The RTRI psychology staffs have developed and revised screening questions for that purpose and investigate standardization and pass-fail criteria, as well as supervised their implementation instruction. This aptitude screening test is composed of the Uchida-Kraepelin psychodiagnostic test, a non-verbal intelligence test, or desktop tests relating to perceptual motor skills and attention distributing acuity. With regard to applicable test data and its relationship with accident participation, a specific criterion-related validity has been discovered 5 .

However, the principles of present aptitude screening systems were established more than half century ago, so the content validity needs to be re-estimated, considering the progress of science and technology, the modernization of railroads and difficult recruitment of railway personnel, and screening test should be implemented more effectively. For the former, we are engaged in full-fledged investigation under the theme "Research for Psychological Aptitude Evaluation Methods Related to Train Operation". For the latter, using personal computers, priority research is being conducted aiming at higher effectiveness in implementation of aptitude screening, collection of related data, evaluation of results, and data management ${ }^{6}$. . However, in the future, this research will be developed in parallel with the former, research of validity.

Testing techniques thus established should also be used for correctly assigning personnel and their professional training. In recent years, tests have been developed focusing on that point. As a result of those efforts, we have the RTRI type Personality test and the RTRI type safety behavior diagnosis ${ }^{7}$. Use of these test results, for the time being, are expected to lead to improvement of test subjects themselves.

As research relating to on-the-job education and training, a Computer Assisted Instruction system has been developed. There is experimental research confirming the accident-preventing effectiveness of finger-pointing and call method which is used to confirm signals and work procedures.

At present, a more systematic approach is being made relating to education and training under the theme of "Development of an Effective Safety Education Program Model for Young Employees".

\section{3 Survey of labor environment and labor conditions}

As a cause of accidents caused by human error, the aspect of the labor environment the workers are placed in is 
extremely critical. Until this point, survey particularly of drivers has been continuously conducted, and the trends in the number of hours worked is being investigated in various operating conditions. Recently, numerous surveys have been conducted from the viewpoint of what effect increased train speed has on operation tasks, but rather than any direct effect due to operating speed, a comprehensive approach by consideration of operating environment or work conditions would seem to be more appropriate. As an evaluation method, methods from the past using heart rate or critical flicker-fusion frequency have been established ${ }^{8,9}$ ), but inferences from the record of motion of eye-gazing behavior of the driver are also valid. In addition, using an easier subjective response survey, we are attempting to make valid inferences ${ }^{10)}$.

These studies of workload evaluation are useful in evaluation of improving the effectiveness of crew scheduling, as well as in study on countermeasures. We can cite studies which attempt to estimate quantitatively accumulated fatigue due to train operation, and make use of that in formulating driver's duty hours ${ }^{11)}$, studies which attempted to confirm effectiveness of chewing gum, as effective measures in maintaining performance while operating a train, as well as developing stretching exercises expected to have the same effect. From the viewpoint of man-machine systems, the following are the current themes for research; designing the engine cabinet instrument from new approach ${ }^{12)}$, ergonomics evaluation regarding improvement of wayside signal equipment 13) as well as development of a checklist for system design 14) intended to integrate automatic expansion.

Furthermore, for railway employees in general, a series of studies have been conducted relating to stress management from the comprehensive viewpoint of their work activities 15$)$.

"A Study of Methods of Evaluating Engineer Workload and Ability to Continue Work" currently being conducted focuses on the relationship between individual resistance to fatigue and whole body endurance. In particular responding to the increase of aged workers, a training program for maintaining and improving physical endurance is viewed as an effective measure, and its development is progressing.

\section{Preventing accidents at crossings}

As a measure for preventing accidents at crossings, structural improvements such as elevated intersections and widening of roads, and installation of safety equipment, including obstruction-detecting device, are steadily progressing. Moreover, the approach of considering the human factor is also making contributions ${ }^{16)}$.

\section{1 Analyzing and managing accident information}

In the same way as operating accidents caused by employees, accurate understanding and analysis of accident information related to crossings is a crucial element in accident prevention research, but currently, sufficient information is not available.

The procedure explained in the previous section can be applied in the same way to accidents at crossings. In other words, as one example, processes leading up to an accident at a crossing are to be formulated in a model; in this case, in contrast to the case where an operation accident was caused by an employee, we can try to discover concrete safety measures ${ }^{17)}$, based on direct survey data of drivers with accident experience (cars, motor vehicles). Furthermore, we statistically analyze the relationship between the data of the equipment of a crossing and its environmental characteristics and the data of accidents which occurred there, in order to develop methods for predicting what type of accident may easily occur at particular crossings ${ }^{18)}$.

\section{2 Controlling passing through a crossing}

In a typical accident that occurs at crossings, the driver of a motor vehicle, affected by lighting conditions or various surroundings of the road, fails to notice the presence of a crossing, warning of approach of a train to a crossing, or is late is discovering them, thereby causing an accident. Crossings with good visibility for drivers have been investigated and studied for long time.

Let us consider warnings at crossings indicating the presence of a train or warning of the approach of train by a sound and light warning signal. Through testing begun on many models in the days before privatization of Japanese National Railways, a new type warning device with both a beacon and warning lamp attached on the tip of the overhang was proposed. A model crossing of this type was placed in service in $1988{ }^{19}$ ). With this kind of stimulus, railway operators as well are putting efforts into improvement of crossing visibility.

With regard to improvement of crossing visibility, we have some experimental studies on design and control of related equipment, including a warning device and their surrounding environment, based upon a cognitive model of drivers passing through a crossing ${ }^{20)}$.

Furthermore, the amount of time the crossing is kept closed is a separate element that influences the behavior of drivers passing through a crossing; in this field, priority is given on the development of procedures not enhancing stress and unreliability of drivers, and not inducing "risk taking" by controlling adequately the timing of warning start and closing start for prevention of accident.

One of the recent achievement worthy of attention is development of a crossing simulator. This simulator, as its primary feature, is capable of predicting the accident probability, and of evaluating the effectiveness of an accidentprotective measure, by handling the parameters such as the traffic on the railway and the road, equipment and structures at a crossing, and the information relating to intersections in the vicinity. In addition, this simulator has a two-dimensional simulation function for the crossing as seen by the driver, and using this device, it is possible to improve the design of a crossing.

Through the above processes, at present a more systematized approach for research is implemented under the theme of "Research of a General Evaluation System of Crossing Safety Measures". 


\section{Aims to reduce calamities in an accident}

On trains in metropolitan areas, it has become important to decrease the time between stations. One effective method for accomplishing this is improving train acceleration and deceleration. In this case, what is the applicable maximum brake force is investigated from the viewpoint of passenger safety and comfort. Even at the same deceleration, depending on the passengers' age, physical strength, posture, and amount of experience, as well as on the state of confusion inside the car, that evaluation will vary, but it is essential to proceed with the investigation from the standpoint of the most disadvantageous passengers in cars. With regard to emergency brakes for preventing accidents, the issue becomes the trade-off between damage avoided by using one and damage caused by using one.

With regard to train collisions and collisions at crossings, both avoiding them and reducing damage due to collisions are is crucial. Conventionally, most emphasis has been placed on accident prevention. Hardly any intense investigation has been conducted of damage reduction at the time of an accident. However, attention has shifted in recent years to this field. Receiving funding from the Ministry of Transport, progress has been made on "Technological Development relating to the Safety of Passengers at the Time of a Collision". Based on the results of collision experiments using a simulation of human body behavior and human dummies at the time of a collision, improvement of vehicle accommodations, and procedures of guiding passengers are also theme of research.

On the other hand, considering major accidents or calamities, with the objective of preparing for a railway transportation crisis in wide areas, "A Study of Crisis Management Simulations for Railway Accidents" has begun. The goal is formulation of a crisis management system based on cognitive science and simulation technology.

\section{References}

1) Hashimoto, K.: "Estimation of the driver's work load in high speed electric car operation on the new Tokaido line in Japan," Proceedings of the 2nd Congress of International Ergonomics Association, pp.463-469, 1964

2) Haga, S.: "Signal vigilance errors by railway drivers," Proceedings of the 8th Congress of the International Ergonomics Association, pp.584-585, 1982

3) Haga, S.: "An experimental study of signal vigilance errors in train driving," Ergonomics, 27, 7, pp.755-765, 1984

4) Watanabe, T., Miyahara, M., Hayashi, Y.: "Causal Structure Analysis of Social Psychological Factors Affecting Railway Workers' Safety Behaviors," Quarterly Report of RTRI, 37, 1, pp.14-20, 1996

5) Yabuhara, A.: "Psychological Aptitude Test adopted in Japanese Railway Industry in quest of Safety and Reliability," Japanese Railway Engineering, 105, pp.5-7, 1988

6) Haga, S.: "Aptitude tests being computerized," Quar- terly Report of RTRI, 33, 3, pp.158-159, 1992

7) Yabuhara, A. Inoue, T., Kon-no, S.: "Relationship between Personality Traits and Safety," Quarterly Report of RTRI, 33, 4, pp.274-279, 1992

8) Inomata, O.: "A Physiological Approach to the Evaluation of Workload, In Coblentz, A.(Ed.): Vigilance and Performance in Automatized Systems," pp.201-206, Kluwer Academic Pub., 1989

9) Tsukamoto, H., Ikeda, M., Kuramata, T., Kashiwamura, S., Sawa, M., Sato, K., Ohkubo, T., Sakai, K.: "Evaluation of operation performance of train operators on the basis of changes in CFF and HR values and the working condition," In Orpana, V., Lukka, A.(Eds.): Production Research 1993, pp.609-610, Elsevier Science Pub., 1993

10) Haga, S., Shinoda, H., Kokubun, M., Fujinami, K.: "Train drivers' accident liability and simple calculation task performance," Proceedings of the 22nd International Congress of Applied Psychology, 6, pp.242-244, 1992

11) Ugajin, H., Ikeda, T., Yoneyama, S.: "Workload management for workers on irregular shifts," In Coblentz, A.(Ed.): Vigilance and Performance in Automatized Systems, pp.191-199, Kluwer Academic Pub., 1989

12) Haga, S.: "Graphic information presentation for train driving on a moving system," Quarterly Report of RTRI, 33, 2, pp.124-128, 1992

13) Ugajin, H., Shiroto, H., Fujinami, K., Omino, K.: "Two Greens; A New Signal Aspect for High-Speed Train on Wayside Signaling," Quarterly Report of RTRI, 40, 1, pp.13-17, 1999

14) Kusukami, K., Ugajin, H., Fujinami, K.: "Introduction of a Human Interface Checklist for System Operators in Large-scale Industries," Abridged Proceedings of the 6th International Conference on Human-Computer Interaction, p.89, 1995

15) Watanabe, T., Tsukamoto, H. Hada, Y.: "Development of Stress Evaluation Scales(2)-Discrimination analysis of circulatory stress patients using urinary chemical and psychological measures-," Quarterly Report of RTRI, 32, 1, pp.42-47, 1991

16) Ikeda, T.: "Human Sciences Approaches to Crossing Safety at JR," Quarterly Report of RTRI, 30, 1, pp.2-8, 1989

17) Inoue, T., Kusukami, K., Kon-no, S.: "Car Driver Behavior in Railway Crossing Accident," Quarterly Report of RTRI, 37, 1, pp.26-31, 1996

18) Kusukami, K.: "Development of Risk Assessment Models for Level Crossing with Automatic Barriers," In Tunna J. M., Hill S. J.(Eds.): Engineering Integrity in Rail Transport Systems, pp.77-92, Engineering Materials Advisory Services LTD., 1992

19) Haga, S.: "A new warning system for protected level crossings," Proceedings of the Human Factors Society 33rd Annual Meeting, 2, pp.975-978, 1989

20) Fukuda, H., Inoue, T., Sato, Y. Hayashi, Y.: "Study on Level Crossing Design and Evaluation Method based on Cognitive Model," Quarterly Report of RTRI, 40, 1, pp.26-31, 1999 